\title{
Effects of different tillage and straw retention practices on soil aggregates and carbon and nitrogen sequestration in soils of the northwestern China
}

\author{
WU Jun ${ }^{1,2}$, Yeboah STEPHEN ${ }^{3}$, CAI Liqun ${ }^{1,2}$, ZHANG Renzhi $^{1,2^{*}}$, QI Peng ${ }^{1}$, LUO Zhuzhu ${ }^{1,2}$, \\ LI Lingling ${ }^{2,4}$, XIE Junhong ${ }^{2,4}$, DONG Bo ${ }^{1}$ \\ ${ }^{1}$ College of Resources and Environmental Sciences, Gansu Agricultural University, Lanzhou 730070, China; \\ ${ }^{2}$ Gansu Provincial Key Lab of Arid land Crop Science, Gansu Agricultural University, Lanzhou 730070, China; \\ ${ }^{3}$ Crops Research Institute, Kumasi 3785, Ghana; \\ ${ }^{4}$ College of Agronomy, Gansu Agricultural University, Lanzhou 730070, China
}

\begin{abstract}
Soil tillage and straw retention in dryland areas may affect the soil aggregates and the distribution of total organic carbon. The aims of this study were to establish how different tillage and straw retention practices affect the soil aggregates and soil organic carbon (SOC) and total nitrogen (TN) contents in the aggregate fractions based on a long-term (approximately 15 years) field experiment in the semi-arid western Loess Plateau, northwestern China. The experiment included four soil treatments, i.e., conventional tillage with straw removed (T), conventional tillage with straw incorporated (TS), no tillage with straw removed (NT) and no tillage with straw retention (NTS), which were arranged in a complete randomized block design. The wet-sieving method was used to separate four size fractions of aggregates, namely, large macroaggregates (LA, >2000 $\mu \mathrm{m}$ ), small macroaggregates (SA, 250-2000 $\mu \mathrm{m}$ ), microaggregates (MA, 53$250 \mu \mathrm{m})$, and silt and clay $(\mathrm{SC},<53 \mu \mathrm{m})$. Compared to the conventional tillage practices (including $\mathrm{T}$ and TS treatments), the percentages of the macroaggregate fractions (LA and SA) under the conservation tillage practices (including NT and NTS treatments) were increased by $41.2 \%-56.6 \%$, with the NTS treatment having the greatest effect. For soil layers of $0-5,5-10$ and $10-30 \mathrm{~cm}$, values of the mean weight diameter (MWD) under the TS and NTS treatments were $10.68 \%, 13.83 \%$ and $17.65 \%$, respectively. They were $18.45 \%, 19.15 \%$ and $14.12 \%$ higher than those under the $\mathrm{T}$ treatment, respectively. The maximum contents of the aggregate-associated SOC and TN were detected in the SA fraction, with the greatest effect being observed for the NTS treatment. The SOC and TN contents were significantly higher under the NTS and TS treatments than under the T treatment. Also, the increases in SOC and TN levels were much higher in the straw-retention plots than in the straw-removed plots. The macroaggregates (including LA and SA fractions) were the major pools for SOC and TN, regardless of tillage practices, storing $3.25-6.81 \mathrm{~g} \mathrm{C} / \mathrm{kg}$ soil and $0.34-0.62 \mathrm{~g} \mathrm{~N} / \mathrm{kg}$ soil. Based on the above results, we recommend the NTS treatment as the best option to boost soil aggregates and to reinforce carbon and nitrogen sequestration in soils in the semi-arid western Loess Plateau of northwestern China.
\end{abstract}

Keywords: soil aggregates; soil organic carbon; total nitrogen; straw management; tillage practices; Loess Plateau

Citation: WU Jun, Yeboah STEPHEN, CAI Liqun, ZHANG Renzhi, QI Peng, LUO Zhuzhu, LI Lingling, XIE Junhong, DONG Bo. 2019. Effects of different tillage and straw retention practices on soil aggregates and carbon and nitrogen sequestration in soils of the northwestern China. Journal of Arid Land, 11(4): 567-578. https://doi.org/10.1007/s40333-019-0065-y

\footnotetext{
*Corresponding author: ZHANG Renzhi (E-mail: zhangrz@gsau.edu.cn)

Received 2018-08-20; revised 2018-12-26; accepted 2019-01-20

(C) Xinjiang Institute of Ecology and Geography, Chinese Academy of Sciences, Science Press and Springer-Verlag GmbH Germany, part of Springer Nature 2019
} 


\section{Introduction}

Several challenges associated with intensive agriculture such as environmental pollution and soil and water resources degradation have led to an increased interest in developing sustainable agriculture. A lower availability of soil nutrients due to inappropriate soil management can destroy soil structure and decrease soil organic matter (Jiang et al., 2011). Soil structure is an important property since it has a significant role in the ability of soil to support plant growth, nutrient uptake and water movement (Kay and Angers, 1988; Shang et al., 2017). Soil aggregation is considered as a crucial process for agro-system sustainability due to the role in soil physical, chemical and biological dynamics (Sarker et al., 2018). Analysis of the stability and particle size distribution of soil aggregates is widely used to assess soil structure (Song et al., 2016). However, the magnitude of the impact of these processes is soil and site specific.

The rain-fed agricultural ecosystem in the semi-arid Loess Plateau of China is fragile and improvement of soil fertility is a key to developing sustainable agriculture. Greater potential exists in the Loess Plateau to enhance the sequestration of carbon and nitrogen in soils with implementation of appropriate tillage methods and crop residue management systems (Jiang et al., 2011; Song et al., 2016). Conservation agriculture is promoted as a set of agricultural practices that include no tillage (NT) or reduced tillage with stubble retention that could increase the soil organic carbon (SOC) pool (Yeboah et al., 2016a) and have a positive effect on aggregate stability and aggregate-associated C (Bottinelli et al., 2017; Somasundaram et al., 2018). Conservation tillage slows the turnover rate of macroaggregates, prevents the decomposition of organic carbon by microbes and extends the storage period of organic carbon in aggregates (Zhang et al., 2013). However, numerous research efforts have presented contradictory findings. For example, BlancoCanqui and Lal (2007) reported that conservation tillage induces less organic carbon storage than conventional tillage throughout the soil profile. Thus, whether conservation tillage can increase organic carbon storage in the soil remains an important issue despite extensive studies have investigated the influence of various tillage practices and crop residue management measures on the content and storage of SOC (Li et al., 2007). Hence, investigating the effects of land use and management modes, in particular, tillage and crop residue application, may lead to better farmland management.

Human activity has large impacts on the ecosystems of the Loess Plateau, China (Zeng et al., 2018). The Loess Plateau is an important rain-fed farmland area due to its contributions to employment and food security for an estimated $1.08 \times 10^{8}$ people in China (Zhao et al., 2012). However, this region is associated with low precipitation and high evaporation coupled with severe erosion, which has led to low farmland productivity (He et al., 2014). Different types of tillage systems affect soil structure and organic matter content, which in turn influence the formation of aggregates (Zheng et al., 2018). Conventional soil cultivation modes have facilitated soil and water erosion processes and resulted in low SOC content and soil fertility (He et al., 2014). Such traditional methods of soil cultivation have progressively reduced the soil resilience and nutrient-holding capacity, thus, having long-term implications for food security in rural communities (McBratney and Field, 2015). The literature is replete with information on the effects of tillage methods and fertilizer management on the soil carbon content and the stability of soil aggregates, but to the best of our knowledge, the effects of tillage with straw retention management on the stability of soil aggregates and aggregate-associated carbon content on cultivated loess soil are still unclear. Studying the changes in the size distribution and stability of soil aggregates, and the $\mathrm{SOC}$ and total nitrogen $(\mathrm{TN})$ contents in different aggregate size fractions under different tillage and straw management practices could provide valuable information on the sustainable use of soil and management modes in the heavily eroded Loess Plateau. Therefore, in this study, a long-term (approximately 15 years) field experiment was conducted in the semi-arid western Loess Plateau to examine the impacts of different tillage practices and straw management schemes on the size distribution and stability of soil aggregates, including the aggregateassociated SOC and TN contents. 


\section{Materials and methods}

\subsection{Study area}

The research was conducted at the Rain-fed Agricultural Experimental Station of Gansu Agricultural University in the semi-arid western Loess Plateau, northwestern China $\left(35^{\circ} 28^{\prime} \mathrm{N}\right.$, $104^{\circ} 44^{\prime} \mathrm{E}$ ). The experiment was initiated in 2001 and, prior to its establishment, flax (Linum usitatissimum L.) was grown on the site. The semi-arid western Loess Plateau is prone to severe soil and water erosion and is characterized by a hilly landscape. The sandy loam and aeolian soil in that region, used primarily as farmland, equates to a Calcaric Cambisol in the FAO Soil Classification (FAO, 1990) and is locally known as Huangmian soil (Chinese Soil Taxonomy Cooperative Research Group, 1995). The chemical characteristics of the soil (0-200 cm depth) for the study area are as follows: average $\mathrm{pH} 8.45$, soil bulk density $1.17 \mathrm{~g} / \mathrm{cm}^{3}$, SOC $8.32 \mathrm{~g} / \mathrm{kg}$, available nitrogen $51.10 \mathrm{mg} / \mathrm{kg}$, available phosphorus $21.19 \mathrm{mg} / \mathrm{kg}$, available potassium 100.90 $\mathrm{mg} / \mathrm{kg}$, TN $0.86 \mathrm{~g} / \mathrm{kg}$, total phosphorus $0.82 \mathrm{~g} / \mathrm{kg}$, total potassium $28.00 \mathrm{~g} / \mathrm{kg}$, wilting point $7.3 \%$ $(\mathrm{w} / \mathrm{w})$ and saturated water content $21.9 \%(\mathrm{w} / \mathrm{w})$. The average annual precipitation and evaporation records at the experimental station are 390.9 and $1531.0 \mathrm{~mm}$, respectively. The annual average temperature is $6.5^{\circ} \mathrm{C}$, with the maximum temperature of $33.3^{\circ} \mathrm{C}$ in July and the minimum temperature of $-26.9^{\circ} \mathrm{C}$ in January. These conditions are representative of those commonly found for agricultural areas with a semi-arid environment.

\subsection{Experimental design}

The experiment was carried out using a spring wheat (Triticum aestivum L.)-field pea (Pisum sativum L.) rotation. The land was cultivated field pea in 2014, spring wheat in 2015 followed by field pea in 2016. The present study was conducted on spring wheat plots in the planting season of 2015. The experiment included four treatments (Table 1): conventional tillage with straw removed (T), conventional tillage with straw incorporated (TS), no tillage with straw removed (NT) and no tillage with straw retention (NTS). All treatments were arranged in a complete randomized block design and each treatment plot area was $80 \mathrm{~m}^{2}(4 \mathrm{~m} \times 20 \mathrm{~m})$. All the plant material from the previous crop was returned to the original plots after threshing and spreading evenly on the soil surface. Each treatment plot was sown by a no tillage seeder.

Table 1 Description of tillage treatments in the experiment

\begin{tabular}{|c|c|c|}
\hline & Treatment & Description \\
\hline $\mathrm{T}$ & $\begin{array}{l}\text { Conventional tillage } \\
\text { with straw removed }\end{array}$ & $\begin{array}{l}\text { The field was ploughed } 3 \text { times and harrowed } 2 \text { times after harvesting. The first plough } \\
\text { was in August immediately after harvesting and the second and third ploughs were in late } \\
\text { August and September, respectively. The plough depths were } 20,10 \text { and } 5 \mathrm{~cm} \text {, respectively. } \\
\text { The field was harrowed after the third plough in September and re-harrowed in October } \\
\text { before the ground became frozen. This was a typical conventional tillage practice in the } \\
\text { western Loess Plateau. }\end{array}$ \\
\hline $\mathrm{TS}$ & $\begin{array}{l}\text { Conventional tillage } \\
\text { with straw } \\
\text { incorporated }\end{array}$ & $\begin{array}{l}\text { The field was ploughed and harrowed exactly as for the } \mathrm{T} \text { treatment, but with straw } \\
\text { incorporated at the first plough. All the straw of the previous crop was returned to the } \\
\text { original plot immediately after threshing and then incorporated into the soil. }\end{array}$ \\
\hline NT & $\begin{array}{l}\text { No tillage with } \\
\text { straw removed }\end{array}$ & No tillage throughout the year. \\
\hline NTS & $\begin{array}{l}\text { No tillage with straw } \\
\text { retention }\end{array}$ & $\begin{array}{l}\text { No tillage throughout the year. The ground was covered with straw from the previous crop } \\
\text { from August until the following March. All the straw from the previous crop was returned } \\
\text { to the original plot immediately after threshing. }\end{array}$ \\
\hline
\end{tabular}

\subsection{Crop sowing and base fertilizers}

Spring wheat was sown at a rate of $187.5 \mathrm{~kg} / \mathrm{hm}^{2}$ (row spacing was $20 \mathrm{~cm}$ ) on 25 March 2015 and harvested on 1 August 2015. Phosphorus and nitrogen fertilizers were applied at the rates of 45.9 $\mathrm{kg} \mathrm{P} / \mathrm{hm}^{2}$ as calcium superphosphate and $105.0 \mathrm{~kg} \mathrm{~N} / \mathrm{hm}^{2}$ as urea for spring wheat, respectively. Field pea was sown at a rate of $180.0 \mathrm{~kg} / \mathrm{hm}^{2}$ (row spacing was $24 \mathrm{~cm}$ ) on 1 April 2014 and harvested on 20 July 2014. Phosphorus and nitrogen fertilizers were applied at the rates of $45.9 \mathrm{~kg}$ 
$\mathrm{P} / \mathrm{hm}^{2}$ as ammonium hydrogen phosphate and $20.0 \mathrm{~kg} \mathrm{~N} / \mathrm{hm}^{2}$ as urea for field pea, respectively. The phosphorus and nitrogen fertilizers were applied simultaneously with the sowing of spring wheat using the same no tillage seeder and incorporated into the soil to a depth of about $10 \mathrm{~cm}$.

Spring wheat was harvested manually using sickles at about $5 \mathrm{~cm}$ above ground level. The edges $(0.5 \mathrm{~m})$ of the treatment plots were trimmed and discarded and then the straw and grain yields were measured with an electronic balance.

\subsection{Soil sampling and measurements}

To measure aggregate stability, we sampled undisturbed soil samples (each sample was about 800 g) randomly with a cylindrical core (diameter: $8 \mathrm{~cm}$; length: $5 \mathrm{~cm})$ at three depths $(0-5,5-10$ and $10-30 \mathrm{~cm}$ ) in each treatment plot from five separate locations. The samples were collected after harvesting of the crop in August 2015. All soil samples were placed in a plastic container to avoid breakdown of the aggregates and then air-dried at $25^{\circ} \mathrm{C}\left( \pm 2^{\circ} \mathrm{C}\right)$. Bulk soil samples (each sample was about $1000 \mathrm{~g})$ were collected randomly with a soil sampler at three depths $(0-5,5-10$ and 10 $30 \mathrm{~cm}$ ) in each treatment plot from five locations. Stones and animal and plant debris were removed before analysis.

The SOC content in the aggregate fractions and the bulk soil were measured using the WalkleyBlack method (1934). The TN content was determined using the Kjeldahl digestion and distillation procedure (Bremner and Breitenbeck, 1983). The saturated hydraulic conductivity was determined using disc permeameter. The soil bulk density was tested using the cutting ring method.

\subsection{Water-stable aggregates}

A wet-sieving method (Elliott and Cambardella, 1991; Cambardella and Elliott, 1994) was used to separate four size fractions of aggregates: large macroaggregate (LA, $>2000 \mu \mathrm{m}$ ), small

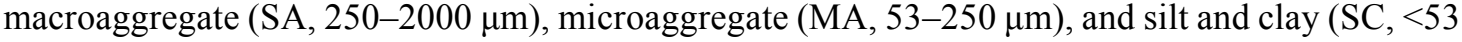
$\mu \mathrm{m})$. A total of $100 \mathrm{~g}$ of the air-dried soil $(<8 \mathrm{~mm})$ was submerged in distilled water on the topmost of a series of three sieves of 2000, 250 and $53 \mu \mathrm{m}$ mesh size for $5 \mathrm{~min}$ (three repetitions per sample). Thereafter, the sieves were shaken vertically up and down (about $3 \mathrm{~cm}$ ) 50 times for $2 \mathrm{~min}$. The soil material on each sieve was washed back into beakers, and the fraction with size $<53 \mu \mathrm{m}$ was collected from the bottom of the water bucket after $48 \mathrm{~h}$. Then, all the materials were oven-dried at $50^{\circ} \mathrm{C}\left( \pm 1^{\circ} \mathrm{C}\right)$ for $48 \mathrm{~h}$. After weighing, the fractions were stored in sample containers for SOC and $\mathrm{TN}$ analyses.

\subsection{Data calculation and statistical analysis}

The mean weight diameter (MWD, mm) was used as a measure of aggregate stability, which was determined by the following equation:

$$
\mathrm{MWD}=\sum_{i=1}^{4} X_{i} W_{i}
$$

where $X_{i}(\mathrm{~mm})$ is the mean diameter of two adjacent fractions and $W_{i}(\%)$ is the percentage of the mass for the $i^{\text {th }}$ aggregate fraction to the total mass for the bulk soil.

The water-stable aggregate fraction (WSA, \%) can be calculated as follows:

$$
\mathrm{WSA}_{i}=\frac{m_{i}}{M_{i}} \times 100 \%,
$$

where $\mathrm{WSA}_{i}(\%)$ is the percentage of each water-stable aggregate fraction; $m_{i}(\mathrm{~g})$ is the mass of the $i^{\text {th }}$ aggregate fraction; and $M_{i}(\mathrm{~g})$ is the mass of the bulk soil in the $i^{\text {th }}$ aggregate fraction.

The stock of an element in the soil aggregate was determined by the following equation:

$$
\mathrm{ESA}_{i}=\frac{\mathrm{WSAE}_{i} \times \mathrm{WSA}_{i}}{100},
$$

where $\mathrm{ESA}_{i}(\mathrm{~g} / \mathrm{kg})$ is the element (SOC or TN) stock in the $i^{\text {th }}$ soil aggregate fraction; $\mathrm{WSAE}_{i}(\mathrm{~g} / \mathrm{kg})$ is the content of the soil element (SOC or TN) in the $i^{\text {th }}$ water-stable aggregate fraction or in the $<53 \mu \mathrm{m}$ fraction; and $\mathrm{WSA}_{i}(\%)$ is the percentage of the $i^{\text {th }}$ water-stable aggregate fraction. 
All statistical analyses were performed using SPSS 19.0 (IBM Corporation, Chicago, USA). Multiple means were compared using two-way analysis of variance (ANOVA). Duncan's multiplerange test was used to ascertain the treatment effects. Statistical significance was determined at the 0.05 level unless stated otherwise.

\section{Results}

\subsection{Distribution of the water-stable aggregates}

For all soil layers, soils under the conservation tillage treatments (NT and NTS) contained more LA, SA and MA fractions than soils under the T treatment; and the differences in the four size fractions were significant for the NTS treatment (Fig. 1). Overall, the SC fraction increased with increase in soil depth, whereas the LA, SA and MA fractions decreased with increase in soil depth. The macroaggregate fractions (LA and SA) comprised the greatest proportion of whole soil for the conservation tillage treatments, accounting for $41.2 \%-56.6 \%$.

In the $0-5 \mathrm{~cm}$ soil layer, the distribution of the four size fractions showed some differences for all treatments (Fig. 1a). The order for the proportions of the four size fractions in the whole soil was $\mathrm{SA}>\mathrm{MA}>\mathrm{LA}>\mathrm{SC}$. For the soil in the layer of $5-10 \mathrm{~cm}$, the NT, TS and NTS treatments had larger proportions of the LA, SA and MA fractions than the T treatment (Fig. 1b). The NTS treatment showed the highest effect, whereas the proportion of SC under the T treatment was higher than those under the conservation tillage treatments (NT and NTS). The NTS treatment had the least proportion of SC. The distribution of the water-stable aggregates for the TS and NTS treatments followed the order of $\mathrm{SA}>\mathrm{MA}>\mathrm{SC}>\mathrm{LA}$ and $\mathrm{SA}>\mathrm{MA}>\mathrm{LA}>\mathrm{SC}$, respectively. The distribution of the four aggregate fractions for the T and NT treatments were in the order of $\mathrm{SC}>\mathrm{SA}>\mathrm{MA}>\mathrm{LA}$. For the $10-30 \mathrm{~cm}$ soil layer, the distribution of the water-stable aggregates reflected the differences between the straw-retention and straw-removal treatments (Fig. 1c).

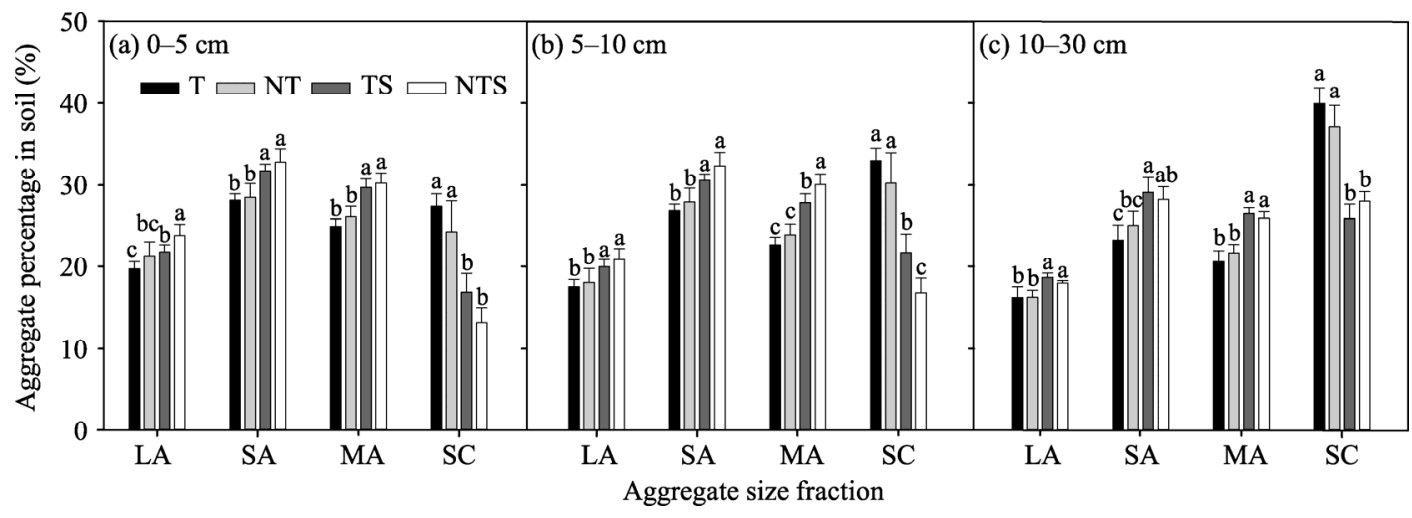

Fig. 1 Size fractions of the water-stable aggregates under different tillage and straw management practices in the soil layers of 0-5 (a), 5-10 (b) and 10-30 cm (c). T, conventional tillage with straw removed; NT, no tillage with straw removed; TS, conventional tillage with straw incorporated; NTS, no tillage with straw retention. LA, large macroaggregate $(>2000 \mu \mathrm{m})$; SA, small macroaggregate $(250-2000 \mu \mathrm{m})$; MA, microaggregate $(53-250 \mu \mathrm{m})$; SC, silt and clay $(<53 \mu \mathrm{m})$. Different lowercase letters represent significant differences among different treatments at $P<0.05$ level for the same water-stable aggregate size fraction. Error bar represents the standard error of the mean $(n=3)$.

\subsection{Stability of the water-stable aggregates}

The ANOVA results showed that the straw retention treatments (TS and NTS) had significant effects on the MWD, regardless of the soil layer (Table 2). The effect of tillage on the MWD was significant only for the soil layer of $0-5 \mathrm{~cm}$, whereas the impact of the interaction between tillage and straw (tillage $\times$ straw) on the MWD was not significant for all soil layers. Across all soil layers, the values of the MWD under the conservation tillage practices (NT and NTS treatments) were higher than those under the conventional tillage practice ( $\mathrm{T}$ treatment). It should be noted that the 
differences of the MWD between the T and NT treatments were not significant, whereas the differences between the T and TS treatments or T and NTS treatments were significant.

For the $0-5 \mathrm{~cm}$ soil layer, the no tillage treatments (NT and NTS) significantly enhanced the MWD values (increased by $5.99 \%$ ) compared to the tillage treatments (T and TS) (Table 2). Compared with the straw-removed treatments (T and NT), the straw-retention treatments (TS and NTS) significantly increased the MWD values by $11.85 \%, 14.66 \%$ and $14.53 \%$ for the $0-5,5-10$ and 10-30 $\mathrm{cm}$ soil layers, respectively. The values of the MWD followed the order of NTS $>$ TS $>$ NT $>$ T treatments for the $0-5$ and $5-10 \mathrm{~cm}$ soil layers. For the $0-5 \mathrm{~cm}$ soil layer, the values of the MWD for the NT, TS and NTS treatments were $4.85 \%, 10.68 \%$ and $18.45 \%$ higher than that for the T treatment, respectively. For the 5-10 cm soil layer, the values of the MWD under the NT, TS and NTS treatments increased by $3.19 \%, 13.83 \%$ and $19.15 \%$, respectively, compared to the T treatment. Moreover, for the 10-30 cm soil layer, the NT, TS and NTS treatments resulted in the increases of the MWD values of $2.35 \%, 17.65 \%$ and $14.12 \%$, respectively, compared to the T treatment.

Table 2 Mean weight diameter (MWD) values of the water-stable aggregates in the 0-5, 5-10 and 10-30 cm soil layers under different tillage and straw management practices

\begin{tabular}{cccc}
\hline \multirow{2}{*}{ Treatment } & & MWD $(\mathrm{mm})$ & $10-30 \mathrm{~cm}$ \\
\cline { 2 - 4 } & $0-5 \mathrm{~cm}$ & $5-10 \mathrm{~cm}$ & $0.85^{\mathrm{b}}$ \\
T & $1.03^{\mathrm{c}}$ & $0.94^{\mathrm{b}}$ & $1.00^{\mathrm{a}}$ \\
TS & $1.14^{\mathrm{b}}$ & $1.07^{\mathrm{a}}$ & $0.87^{\mathrm{b}}$ \\
NT & $1.08^{\mathrm{bc}}$ & $0.97^{\mathrm{b}}$ & $0.97^{\mathrm{a}}$ \\
NTS & $1.22^{\mathrm{a}}$ & $1.12^{\mathrm{a}}$ & $\mathrm{ns}$ \\
Tillage & $* *$ & $\mathrm{~ns}$ & $* * *$ \\
Straw & $* * *$ & $\mathrm{~ns}$ & $\mathrm{~ns}$ \\
Tillage $\times$ Straw & $\mathrm{ns}$ & $\mathrm{ns}$ & \\
\hline
\end{tabular}

Note: Means with different lowercase letters in the same column represent significant differences at $P<0.05$ level. **, significant at $P<0.01$ level; ***, significant at $P<0.001$ level; ns, not significant at $P<0.05$ level. $n=3$.

\subsection{SOC and TN contents}

\subsubsection{SOC and TN contents in the bulk soil}

The two-factor ANOVA showed that tillage significantly influenced the SOC and TN contents of the bulk soil in the first two soil layers $(0-5$ and $5-10 \mathrm{~cm})$ and in the first soil layer $(0-5 \mathrm{~cm})$, respectively (Table 3), while straw had significant effects on the SOC and TN contents for all observed soil layers. The tillage $\times$ straw combination had no significant effect on the SOC and TN contents for all soil layers. The SOC and TN contents of the bulk soil followed a similar trend as the MWD.

Table 3 Soil organic carbon (SOC) and total nitrogen (TN) contents of the bulk soil in the 0-5, 5-10 and 10-30 $\mathrm{cm}$ soil layers under different tillage and straw management practices

\begin{tabular}{|c|c|c|c|c|c|c|}
\hline \multirow{2}{*}{ Treatment } & \multicolumn{3}{|c|}{ SOC (g/kg) } & \multicolumn{3}{|c|}{$\mathrm{TN}(\mathrm{g} / \mathrm{kg})$} \\
\hline & $0-5 \mathrm{~cm}$ & $5-10 \mathrm{~cm}$ & $10-30 \mathrm{~cm}$ & $0-5 \mathrm{~cm}$ & $5-10 \mathrm{~cm}$ & $10-30 \mathrm{~cm}$ \\
\hline $\mathrm{T}$ & $9.24^{\mathrm{d}}$ & $8.11^{\mathrm{d}}$ & $7.49^{c}$ & $0.83^{\mathrm{c}}$ & $0.75^{\mathrm{b}}$ & $0.73^{\mathrm{b}}$ \\
\hline $\mathrm{TS}$ & $10.56^{\mathrm{b}}$ & $9.76^{\mathrm{b}}$ & $9.10^{\mathrm{a}}$ & $0.88^{\mathrm{b}}$ & $0.84^{\mathrm{a}}$ & $0.79^{\mathrm{a}}$ \\
\hline NT & $9.91^{\mathrm{c}}$ & $8.53^{\mathrm{c}}$ & $7.79^{\mathrm{b}}$ & $0.86^{\mathrm{bc}}$ & $0.77^{\mathrm{b}}$ & $0.74^{\mathrm{b}}$ \\
\hline NTS & $11.58^{\mathrm{a}}$ & $10.42^{\mathrm{a}}$ & $8.87^{\mathrm{a}}$ & $0.92^{\mathrm{a}}$ & $0.87^{\mathrm{a}}$ & $0.80^{\mathrm{a}}$ \\
\hline Tillage & $* * *$ & $* * *$ & ns & $* *$ & ns & ns \\
\hline Straw & $* * *$ & $* * *$ & $* * *$ & $* * *$ & $* * *$ & ** \\
\hline Tillage $\times$ Straw & ns & ns & ns & $\mathrm{ns}$ & ns & $\mathrm{ns}$ \\
\hline
\end{tabular}

Note: Means with different lowercase letters in the same column represent significant differences at $P<0.05$ level. **, significant at $P<0.01$ level; ***, significant at $P<0.001$ level; ns, not significant at $P<0.05$ level. $n=3$.

Compared with the tillage treatments (T and TS), the no tillage treatments (NT and NTS) resulted in significant improvements in the SOC contents of the bulk soil, that is, increases of $8.54 \%$ and 
$6.04 \%$ for the $0-5$ and 5-10 cm layers, respectively. Compared to the straw-removed treatments (T and NT), the straw-retention treatments (TS and NTS) significantly enhanced the SOC contents in the bulk soil by $15.61 \%, 21.27 \%$ and $17.60 \%$ for the $0-5,5-10$ and $10-30 \mathrm{~cm}$ soil layers, respectively. In the $0-5 \mathrm{~cm}$ soil layer, the TN contents under the no tillage treatments (NT and NTS) increased significantly (by $4.09 \%$ ) compared to those under the tillage treatments (T and TS). In the $0-5,5-10$ and $10-30 \mathrm{~cm}$ soil layers, the TN contents of the bulk soil under the straw-retention treatments (TS and NTS) were $6.51 \%, 12.50 \%$ and $8.16 \%$ higher than those under the non-straw retained treatments ( $\mathrm{T}$ and $\mathrm{NT}$ ), respectively.

\subsubsection{SOC and $\mathrm{TN}$ contents in the water-stable aggregates}

Tillage affected significantly the aggregate-associated SOC and TN contents in the first two layers $(0-5$ and 5-10 $\mathrm{cm})$, but it had no effect in the third soil layer $(10-30 \mathrm{~cm})$ (Table 4). Straw and aggregate size had significant effects on the aggregate-associated SOC and TN contents in all soil layers. However, the possible interactions between tillage, straw and aggregate size had no significant effects on the aggregate-associated $\mathrm{TN}$ content. In all soil layers, the aggregateassociated SOC and TN contents in the different fractions exhibited the same distribution pattern with the order of $\mathrm{SA}>\mathrm{MA}>\mathrm{LA}>\mathrm{SC}$ (Fig. 2). For all treatments, the SOC and TN contents within the four aggregate fractions decreased with increasing soil depth. Compared with $\mathrm{T}$ treatment, the NT, TS and NTS treatments showed higher contents of aggregate-associated SOC and TN, and the differences of the SOC content within aggregates between the T and TS treatments or T and NTS treatments were significant for all soil layers. However, the difference of aggregate-associated TN content was significant for the T and NTS treatments only for the first two soil layers. Moreover, for all treatments, the NTS treatment showed the highest contents of aggregate-associated SOC and $\mathrm{TN}$ in the first two layers, and the TS treatment showed the highest SOC and TN contents in the third soil layer.

Table 4 Effects of tillage, straw, aggregate size and the possible interaction of the variables on the aggregateassociated SOC and TN contents in the $0-5,5-10$ and $10-30 \mathrm{~cm}$ soil layers

\begin{tabular}{|c|c|c|c|c|c|c|}
\hline \multirow{2}{*}{ Factor } & \multicolumn{3}{|c|}{ SOC in the water-stable aggregates } & \multicolumn{3}{|c|}{$\mathrm{TN}$ in the water-stable aggregates } \\
\hline & $0-5 \mathrm{~cm}$ & $5-10 \mathrm{~cm}$ & $10-30 \mathrm{~cm}$ & $0-5 \mathrm{~cm}$ & $5-10 \mathrm{~cm}$ & $10-30 \mathrm{~cm}$ \\
\hline Tillage & $* * *$ & $* * *$ & ns & $* * *$ & $* * *$ & ns \\
\hline Straw & $* * *$ & $* * *$ & $* * *$ & $* * *$ & $* * *$ & $* * *$ \\
\hline Size & $* * *$ & $* * *$ & $* * *$ & $* * *$ & $* * *$ & $* * *$ \\
\hline Tillage $\times$ Straw & $* * *$ & $*$ & $*$ & ns & ns & ns \\
\hline Tillage $\times$ Size & $*$ & ns & ns & ns & ns & ns \\
\hline Straw $\times$ Size & $* * *$ & $* * *$ & $* * *$ & ns & ns & ns \\
\hline
\end{tabular}

Note: *, significant at $P<0.05$ level; ***, significant at $P<0.001$ level; ns, not significant at $P<0.05$ level.

\subsubsection{Correlations of SOC and TN with aggregate size fractions and MWD}

The correlations of SOC and TN contents with aggregate size fractions (LA, SA, MA and SC) and MWD were examined by calculating the respective Pearson's correlation coefficients (Table 5). Generally speaking, the SOC and TN contents showed significant positive correlations with LA, SA, MA and MWD. The SOC and TN contents decreased significantly in the SC fraction.

\subsection{SOC and TN stocks in the water-stable aggregates}

The SOC stock and TN stock in the water-stable aggregate size fractions showed similar distribution patterns (Fig. 3). The SOC and TN stocks in the LA, SA and MA fractions decreased with increasing soil depth. Among the water-stable aggregate fractions, the macroaggregates (LA and SA) held the major SOC and TN pools, regardless of tillage practices. Specifically, the LA and SA fractions held 3.25-6.81 g C/kg soil and $0.34-0.62 \mathrm{~g} \mathrm{~N} / \mathrm{kg}$ soil, respectively, accounting for $43.37 \%-58.83 \%$ of the SOC stock and $39.90 \%-56.84 \%$ of the TN stock in the bulk soil. Generally, the TS and NTS treatments enhanced significantly the SOC and TN stocks in the LA, SA and MA fractions compared to the T and NT treatments. Furthermore, the TS and NTS treatments showed the highest SOC and TN stocks in all soil layers. 

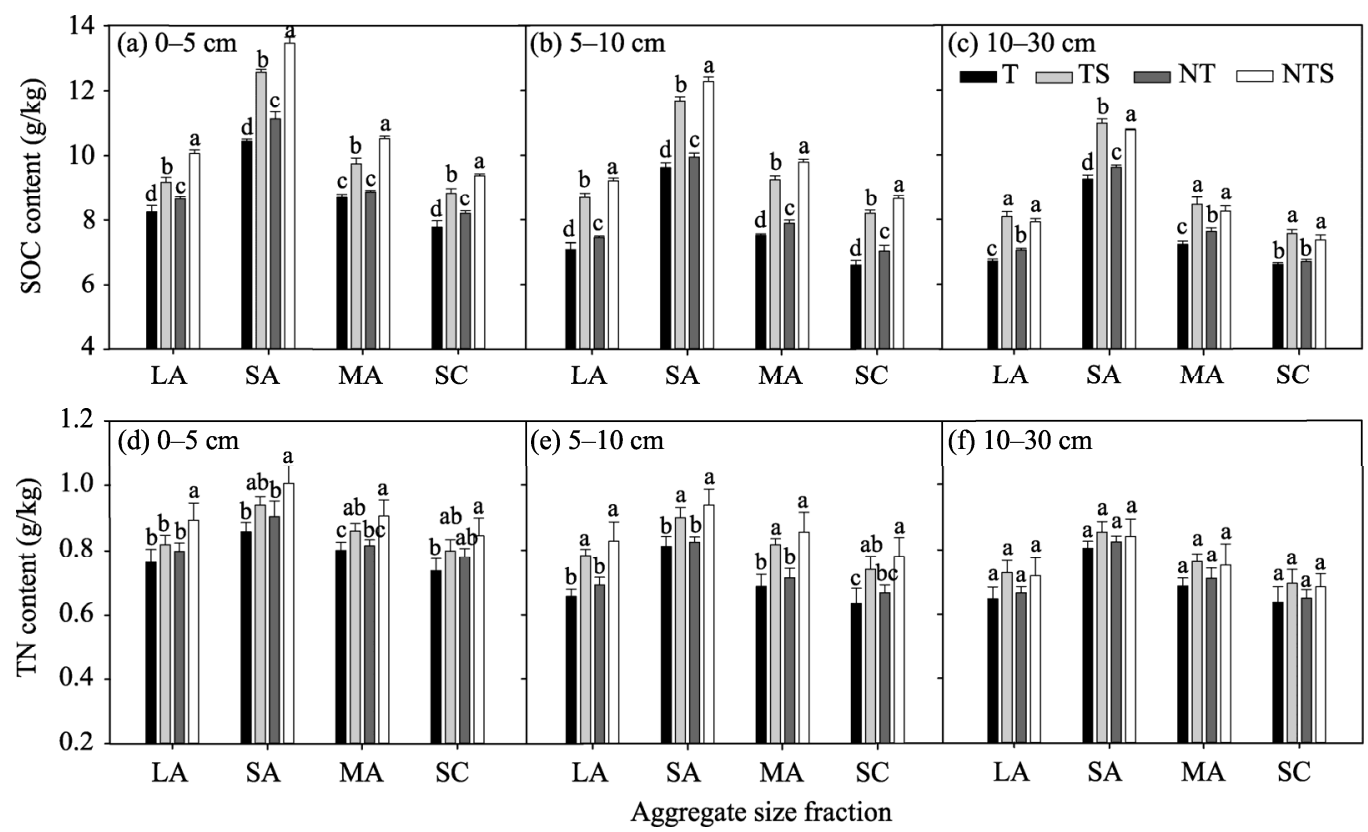

Fig. 2 Contents of aggregate-associated SOC (a-c) and TN (d-f) in the different water-stable aggregate fractions in the $0-5,5-10$ and $10-30 \mathrm{~cm}$ soil layers under different tillage and straw management practices. SOC, soil organic carbon; TN, total nitrogen. Different lowercase letters represent significant differences among different treatments at $P<0.05$ level for the same water-stable aggregate size fraction. Error bar represents the standard error of the mean $(n=3)$.

Table 5 Pearson's correlations of SOC and TN contents with aggregate size fractions and MWD

\begin{tabular}{cccccc}
\hline & LA & SA & MA & SC & MWD \\
\hline SOC & $0.97^{* *}$ & $0.94^{* *}$ & $0.96^{* *}$ & $-0.97^{* *}$ & $0.99^{* *}$ \\
TN & $0.97^{* *}$ & $0.89^{* *}$ & $0.93^{* *}$ & $-0.93^{* *}$ & $0.99^{* *}$ \\
\hline
\end{tabular}

Note: LA, large macroaggregates $(>2000 \mu \mathrm{m})$; SA, small macroaggregates $(250-2000 \mu \mathrm{m})$; MA, microaggregates $(53-250 \mu \mathrm{m})$; SC, silt and clay $(<53 \mu \mathrm{m}) .{ }^{* *}$, significant at $P<0.01$ level.

\section{Discussion}

The soil aggregate stability and nutrient content are affected by management practices (tillage and straw retention), and this may decide farmland productivity through their influence on the soil microbial activity and soil health (Zhang et al., 2012). In this study, because tillage caused the breakdown of the macroaggregates into smaller size fractions, it was found that compared with the $\mathrm{T}$ treatment, conservation tillage treatments (NT and NTS) enhanced the percentage of each aggregate size fraction, and that macroaggregates (LA and SA) were the dominant fraction. Conservation tillage generally improves soil aggregation and aggregate stability as it reduces soil disturbance and soil mixing. Additionally, straw application may also improve aggregate stability by reducing the exposure of soil organic matter to direct wet-dry and freeze-thaw cycles by presenting a barrier between the soil surface and the atmosphere. This result is consistent with the study of Devine et al. (2010), who reported a higher proportion of the $>250 \mu \mathrm{m}$ aggregate size fractions. The present results also suggest that addition of organic matter improves soil aggregation processes as a result of the organic matter acting as binding agents for soil aggregation (Tisdall and Oades, 1982). This suggests that conservation tillage could potentially decrease the macroaggregate turnover in farmlands and consequently facilitate the sequestration of organic carbon. Compared with non-straw-treated treatments, straw retention treatments with long-term no tillage significantly enhanced the LA, SA and MA fractions and the MWD. Application of straw to loess soil, in particular, has been noted to increase the SOC and TN contents (Zhang et al., 2013). Straw application also has beneficial effects on the SOC sequestration, as a result of strongly 

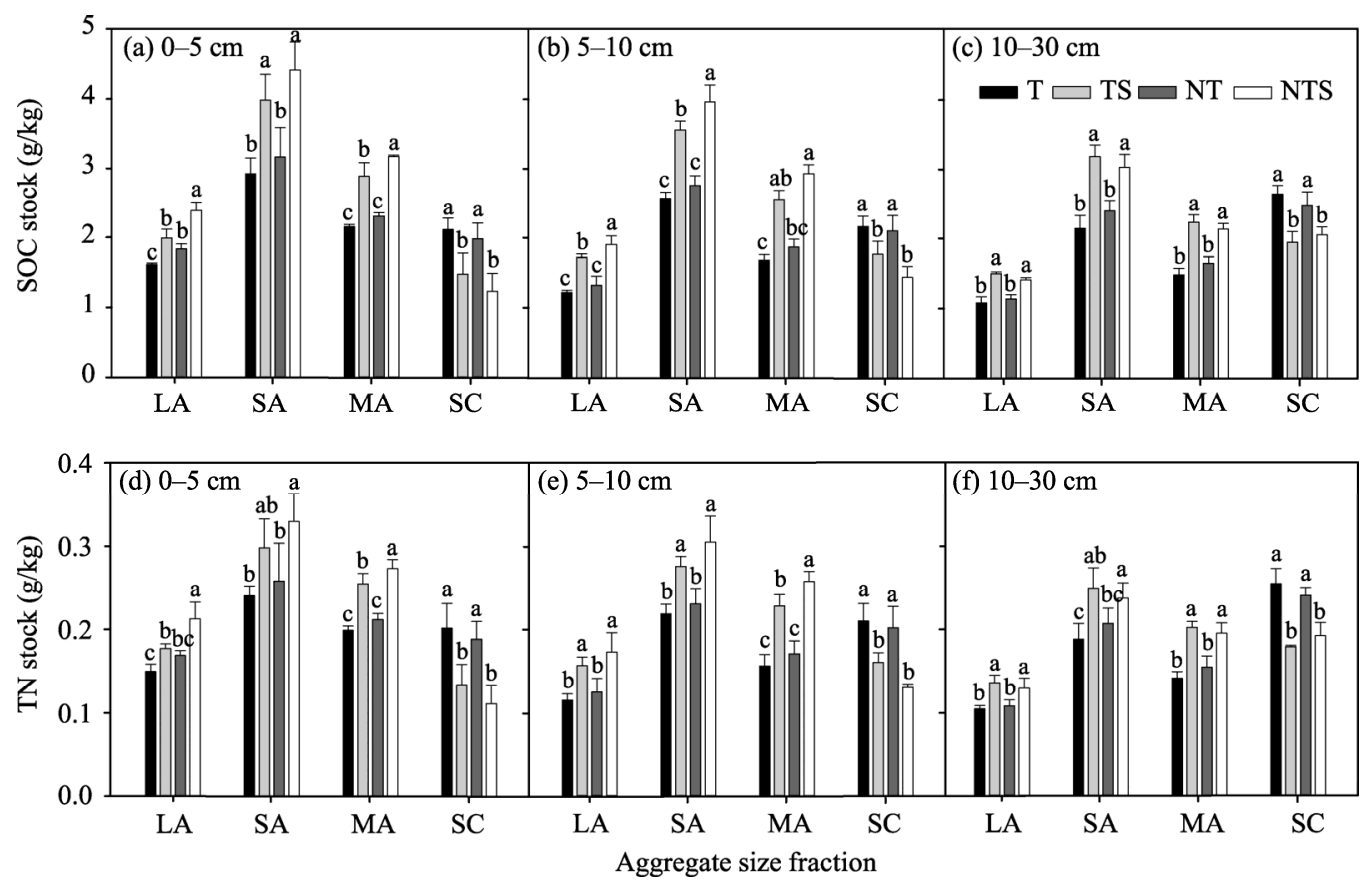

Fig. 3 SOC and TN stocks of different water-stable aggregate fractions in the $0-5,5-10$ and $10-30 \mathrm{~cm}$ soil layers under different tillage and straw management practices. Different lowercase letters represent significant differences among the different treatments at $P<0.05$ level in the same water-stable aggregate size fraction. Error bar represents the standard error of the mean $(n=3)$.

influencing the temporal patterns of $\mathrm{CO}_{2}$ emissions from soil (Jacinthe et al., 2002). A similar observation was made in the same study area by Yeboah et al. (2016a). Present results are also similar to those in a report by Bhattacharyya et al. (2013) who observed that 4 years of straw retention coupled with reduced tillage practices enhanced soil carbon and nitrogen relative to conventional methods. Thus, the addition of organic residue matter improves soil structure and increases aggregate stability. In the present study, the main effects of straw retention were on increasing soil aggregation and stability. Several studies have shown that no tillage accompanied by straw application results in a greater SOC sequestration because improved aggregation protects SOC from mineralization compared to conventional tillage (Yeboah et al., 2016a, b). The mechanism behind the increase in soil aggregation and stability in straw retention treatment may be attributed to the release of polysaccharides and organic acids, which enhance substrate availability for microbial growth. These effects concurrently promote the formation of macroaggregates through the binding of straw and soil particles (Song et al., 2016). In this study, the SC fraction $(<53 \mu \mathrm{m})$ increased with increasing depth of the studied soil layers, and all other aggregate fractions decreased with increasing depth of the studied soil layers; however, the effect was larger for the NTS treatment. The results indicate that the contents of stable macroaggregates can be increased by no tillage treatment coupled with crop residue application (Bandyopadhyay et al., 2010). The water-stable aggregates were greater for the NTS treatment for the first two soil layers $(0-5$ and $5-10 \mathrm{~cm})$, whereas there were more water-stable aggregates in the TS treatment for the soil layer of $10-30 \mathrm{~cm}$. Consequently, conservation tillage may stabilize aggregates by the following mechanisms: (1) no tillage reduces the disturbances normally caused by plowing (Bottinelli et al., 2017) and improves the functions of intrinsic soil restoration processes; (2) covering of the field with straw reduces the impact of raindrops on the topsoil under the NTS treatment, and decreases the effects of frequent freeze-thaw and wet-dry cycles on the topsoil (Song et al., 2016); and (3) SOC is a good predictor of both soil aggregate stability and cohesion (Nouwakpo et al., 2018), and a higher soil organic matter content results in enhanced binding which is critical for soil aggregation (Meng et al., 2014). 
The SOC and TN contents in aggregates under different tillage practices showed a similar trend with the distribution pattern of aggregates. This supports the work of Song et al. (2016), who reported that in the $0-15 \mathrm{~cm}$ soil layer, the greatest proportion of total organic carbon in the aggregates followed a similar trend to that of the MWD in rice-wheat rotation grown under a double-conservation tillage. In this study, greater aggregate-associated SOC and TN contents were found in the macroaggregates $(>250 \mu \mathrm{m})$. The slower turnover of macroaggregates may enhance the formation of highly stable microaggregates, in which the carbon is stabilized and sequestered in the long period. This result is consistent with the findings of Devine et al. (2014) who reported higher levels of SOC in the macroaggregates $(>250 \mu \mathrm{m})$.

In contrast to the above-mentioned results, Aminiyan et al. (2015) reported higher levels of aggregate-associated SOC in the larger aggregate size fractions $(>2000 \mu \mathrm{m})$. This result indicated that the macroaggregate fractions contain a higher amount of organic carbon than the microaggregate fractions. This may be caused by enhanced strength or stability of aggregates due to the humidification of crop residues, which improves the amount of organic carbon in the macroaggregates in the treated soil (Kushwaha et al., 2001). In addition, in contrast to the larger aggregates, the smaller aggregates contain smaller carbon aggregates (Bronick and Lal, 2005).

In this study, there were differences in the SOC and TN contents in the macroaggregates between the conservation tillage practices, but the effect was most pronounced for no tillage with straw retention treatment. This was because the straw-retained treatment under the no tillage practice resulted in a reduction in the deterioration of soil aggregates, thereby the stability and content of the associated SOC were enhanced. This finding agrees with other studies where it was found that the effects of tillage on the soil nutrient content and organic carbon varied highly among aggregates (Devine et al., 2014; Song et al., 2016). Our studies also found that regardless of tillage practices, the greatest contents of SOC and TN were in the SA $(250-2000 \mu \mathrm{m})$ fraction for all soil layers. This finding indicates that the macroaggregates constitute the major portion of the SOC and TN pools, regardless of the tillage practices. Six et al. (2000) suggested that the main carriers of SOC are the microaggregate fractions. For soils in the layer of $10-30 \mathrm{~cm}$, the TS treatment resulted in more soil aggregates than the T treatment. Present results also show that with increases in the straw incorporation or retention, the SOC and TN contents were also enhanced, and the aggregateassociated SOC content was increased. The higher levels of SOC and TN in the straw retention treatments support the hypothesis that increased carbon inputs result in an enhanced SOC content. For the study area, Yeboah et al. (2016b) also found that, compared with the conventional tillage, 14 years of reduced tillage led to a greater SOC content in the upper soil layer. The results could be due to a lower content of soil water-stable aggregates and organic carbon as a result of the conventional tillage treatment.

Previous research has shown that the conservation tillage can boost farmland productivity (Yeboah et al., 2016b). In the present study, compared to the conventional treatments with straw removed, straw retention in soils improved the grain yield and saturated hydraulic conductivity, and decreased the soil bulk density (Tables 6 and 7). Moreover, no tillage combined with residue retention improved and stabilized crop yields under rain-fed conditions. The differences in grain and stubble yields may be related to the improved soil quality (Yeboah et al., 2016b). The results of the present study indicate that in semi-arid areas, no tillage with straw retention has a significant effect on the distribution patterns of the soil quality parameters reported here and may play a crucial role in sustaining agricultural productivity.

Table 6 Straw and grain yield of spring wheat under different tillage and straw management practices

\begin{tabular}{cll}
\hline \multirow{2}{*}{ Treatment } & \multicolumn{2}{c}{ Yield $\left(\mathrm{kg} / \mathrm{hm}^{2}\right)$} \\
\cline { 2 - 3 } & Straw & Grain \\
\hline T & $4485^{\mathrm{c}}$ & $1275^{\mathrm{b}}$ \\
TS & $6028^{\mathrm{b}}$ & $1980^{\mathrm{a}}$ \\
NT & $4782^{\mathrm{c}}$ & $1346^{\mathrm{b}}$ \\
NTS & $6442^{\mathrm{a}}$ & $2078^{\mathrm{a}}$ \\
\hline
\end{tabular}


Table 7 Effects of different tillage and straw management practices on soil bulk density and saturated hydraulic conductivity

\begin{tabular}{|c|c|c|c|c|c|c|c|c|c|c|c|c|}
\hline \multirow{3}{*}{ Treatment } & \multicolumn{9}{|c|}{ Soil bulk density $\left(\mathrm{g} / \mathrm{cm}^{3}\right)$} & \multicolumn{3}{|c|}{ Saturated hydraulic conductivity $(\mathrm{mm} / \mathrm{h})$} \\
\hline & \multicolumn{3}{|c|}{$0-5 \mathrm{~cm}$} & \multicolumn{3}{|c|}{$5-10 \mathrm{~cm}$} & \multicolumn{3}{|c|}{$10-30 \mathrm{~cm}$} & \multirow{2}{*}{2014} & \multirow{2}{*}{2015} & \multirow{2}{*}{ Mean } \\
\hline & 2014 & 2015 & Mean & 2014 & 2015 & Mean & 2014 & 2015 & Mean & & & \\
\hline $\mathrm{T}$ & $1.29^{\mathrm{a}}$ & $1.31^{\mathrm{a}}$ & $1.30^{\mathrm{a}}$ & $1.31^{\mathrm{a}}$ & $1.36^{\mathrm{a}}$ & $1.34^{\mathrm{a}}$ & $1.37^{\mathrm{a}}$ & $1.36^{\mathrm{a}}$ & $1.37^{\mathrm{a}}$ & $57.51^{\mathrm{c}}$ & $68.06^{\mathrm{c}}$ & $62.78^{\mathrm{c}}$ \\
\hline TS & $1.17^{\mathrm{c}}$ & $1.26^{\mathrm{a}}$ & $1.22^{\mathrm{b}}$ & $1.20^{\mathrm{b}}$ & $1.27^{\mathrm{b}}$ & $1.24^{\mathrm{b}}$ & $1.31^{\mathrm{a}}$ & $1.34^{\mathrm{a}}$ & $1.34^{\mathrm{a}}$ & $63.84^{\mathrm{b}}$ & $75.38^{\mathrm{b}}$ & $69.61^{\mathrm{bc}}$ \\
\hline NT & $1.24^{\mathrm{b}}$ & $1.27^{\mathrm{a}}$ & $1.26^{\mathrm{a}}$ & $1.30^{\mathrm{a}}$ & $1.29^{b}$ & $1.30^{\mathrm{a}}$ & $1.37^{\mathrm{a}}$ & $1.29^{\mathrm{a}}$ & $1.32^{\mathrm{a}}$ & $72.68^{b}$ & $76.17^{\mathrm{ab}}$ & $74.43^{b}$ \\
\hline NTS & $1.15^{\mathrm{c}}$ & $1.11^{\mathrm{b}}$ & $1.13^{\mathrm{c}}$ & $1.17^{\mathrm{c}}$ & $1.16^{\mathrm{c}}$ & $1.17^{\mathrm{c}}$ & $1.21^{\mathrm{a}}$ & $1.22^{\mathrm{a}}$ & $1.22^{\mathrm{a}}$ & $86.06^{\mathrm{a}}$ & $88.66^{\mathrm{a}}$ & $87.36^{\mathrm{a}}$ \\
\hline
\end{tabular}

Note: Different lowercase letters in the same column represent significant differences at $P<0.05$ level among different treatments. $n=3$.

\section{Conclusions}

Low contents of SOC and TN and consequently weak soil structural stability are common attributes of semi-arid soils. The effect of 15 years of conservation tillage practices have led to changes in the SOC content and the aggregate characteristics of soils in the western Loess Plateau, northwestern China. Our results show that the NTS treatment enhanced the contents of SOC and $\mathrm{TN}$ in the soil macroaggregates. The NTS treatment and, to a lesser extent, the TS treatment increased significantly soil macroaggregation and the levels of aggregate-associated SOC and TN compared with the T treatment. These treatments also enhanced the MWD. The NTS treatment increased straw and grain yields compared with the NT and T treatments, but these were not significantly different from those of the TS treatment. The result that the higher levels of SOC and $\mathrm{TN}$ in the macroaggregate size fractions for the NTS treatment compared to the T treatment implies that the NTS treatment may be the ideal route for the enhancement of farmland productivity in semi-arid soil ecosystems as a result of improved soil structure. This would result in the maintenance of high nutrient levels and thus would subsequently help to achieve higher crop yields in semi-arid lands.

\section{Acknowledgements}

This research was financially supported by the Scientific Research Start-up Funds for Openly-Recruited Doctors (GAU-KYQD-2018-39), the National Natural Science Foundation of China $(31571594,41661049)$ and the National Science and Technology Supporting Program of China (2015BAD22B04-03).

\section{References}

Aminiyan M M, Sinegani A A S, Sheklabadi M. 2015. Aggregation stability and organic carbon fraction in a soil amended with some plant residues, nanozeolite, and natural zeolite. International Journal of Recycling of Organic Waste in Agriculture, 4(1): $11-22$.

Bandyopadhyay P K, Saha S, Mani P K, et al. 2010. Effect of organic inputs on aggregate associated organic carbon concentration under long-term rice-wheat cropping system. Geoderma, 154(3-4): 379-386.

Bhattacharyya R, Das T K, Pramanik P, et al. 2013. Impacts of conservation agriculture on soil aggregation and aggregateassociated $\mathrm{N}$ under an irrigated agroecosystem of the Indo-Gangetic Plains. Nutrient Cycling in Agroecosystems, 96(2-3): 185-202.

Blanco-Canqui H, Lal R. 2007. Soil structure and organic carbon relationships following 10 years of wheat straw management in no-till. Soil and Tillage Research, 95(1-2): 240-254.

Bottinelli N, Angers D A, Hallaire V, et al. 2017. Tillage and fertilization practices affect soil aggregate stability in a Humic Cambisol of Northwest France. Soil and Tillage Research, 170: 14-17.

Bremner J M, Breitenbeck G A. 1983. A simple method for determination of ammonium in semimicro-Kjeldahl analysis of soils and plant materials using a block digester. Communications in Soil Science and Plant Analysis, 14(10): $905-913$.

Bronick C J, Lal R. 2005. Soil structure and management: a review. Geoderma, 124(1): 3-22.

Cambardella C A, Elliott E T. 1994. Carbon and nitrogen dynamics of soil organic matter fractions from cultivated grassland soils. Soil Science Society of America Journal, 58(1): 123-130. 
Chinese Soil Taxonomy Cooperative Research Group. 1995. Chinese Soil Taxonomy (Revised Proposal). Beijing: Chinese Agricultural Science and Technology Press, 137-145. (in Chinese)

Devine S, Markewitz D, Hendrix P, et al. 2014. Soil aggregates and associated organic matter under conventional tillage, notillage, and forest succession after three decades. PloS ONE, 9(1): e84988.

Elliott E T, Cambardella C A. 1991. Physical separation of soil organic matter. Agriculture, Ecosystems \& Environment, 34(14): $407-419$.

FAO. 1990. Soil map of the world: revised legend. World Soil Resources Report 60. Food and Agriculture Organization of the United Nations, Rome.

He L, Cleverly J, Chen C, et al. 2014. Diverse responses of winter wheat yield and water use to climate change and variability on the semiarid Loess Plateau in China. Agronomy Journal, 106(4): 1169-1178.

Jacinthe P A, Lal R, Kimble J M. 2002. Carbon dioxide evolution in runoff from simulated rainfall on long-term no-till and plowed soils in southwestern Ohio. Soil and Tillage Research, 66(1): 23-33.

Jiang X, Hu Y, Bedell J H, et al. 2011. Soil organic carbon and nutrient content in aggregate-size fractions of a subtropical rice soil under variable tillage. Soil Use and Management, 27(1): 28-35.

Kay B D, Angers D A, Groenevelt P H, et al. 1988. Quantifying the influence of cropping history on soil structure. Canadian Journal of Soil Science, 68(2):359-368.

Kushwaha C P, Tripathi S K, Singh K P. 2001. Soil organic matter and water-stable aggregates under different tillage and residue conditions in a tropical dryland agroecosystem. Applied Soil Ecology, 16(3): 229-241.

Li X G, Wang Z F, Ma Q F, et al. 2007. Crop cultivation and intensive grazing affect organic C pools and aggregate stability in arid grassland soil. Soil and Tillage Research, 95(1-2): 172-181.

McBratney A, Field D. 2015. Securing our soil. Soil Science and Plant Nutrition, 61(4): 587-591.

Meng Q, Sun Y, Zhao J, et al. 2014. Distribution of carbon and nitrogen in water-stable aggregates and soil stability under longterm manure application in solonetzic soils of the Songnen plain, northeast China. Journal of Soils and Sediments, 14(6): 10411049.

Nouwakpo S K, Song J, Gonzalez J M. 2018. Soil structural stability assessment with the fluidized bed, aggregate stability, and rainfall simulation on long-term tillage and crop rotation systems. Soil and Tillage Research, 178: 65-71.

Sarker T C, Incerti G, Spccini R, et al. 2018. Linking organic matter chemistry with soil aggregate stability: Insight from ${ }^{13} \mathrm{C}$ NMR spectroscopy. Soil Biology and Biochemistry, 117: 175-184.

Shang W, Li Y, Zhao X, et al. 2017. Effects of Caragana microphylla plantations on organic carbon sequestration in total and labile soil organic carbon fractions in the Horqin Sandy Land, northern China. Journal of Arid Land, 9(5): 688-700.

Six J, Paustian K, Elliott E T, et al. 2000. Soil structure and organic matter I. Distribution of aggregate-size classes and aggregateassociated carbon. Soil Science Society of America Journal, 64(2): 681-689.

Somasundaram J, Chaudhary R S, Kumar D A, et al. 2018. Effect of contrasting tillage and cropping systems on soil aggregation, carbon pools and aggregate-associated carbon in rainfed Vertisols. European Journal of Soil Science, 69(5): 879-891.

Song K, Yang J, Xue Y, et al. 2016. Influence of tillage practices and straw incorporation on soil aggregates, organic carbon, and crop yields in a rice-wheat rotation system. Scientific Reports, 6: 36602.

Tisdall J M, Oades J M. 1982. Organic matter and water-stable aggregates in soils. Journal of Soil Science, 33(2): $141-163$.

Walkley A, Black I A. 1934. An examination of the method for determining soil organic matter, and a proposed modification of the chromic acid titration method. Soil Science, 37: 29-38.

Yeboah S, Zhang R, Cai L, et al. 2016a. Greenhouse gas emissions in a spring wheat-field pea sequence under different tillage practices in semi-arid Northwest China. Nutrient Cycling in Agroecosystems, 106(1): 77-91.

Yeboah S, Zhang R, Cai L, et al. 2016b. Tillage effect on soil organic carbon, microbial biomass carbon and crop yield in spring wheat-field pea rotation. Plant Soil Environment, 62(6): 279-285.

Zeng Q C, Darboux F, Man C, et al. 2018. Soil aggregate stability under different rain conditions for three vegetation types on the Loess Plateau (China). Catena, 167: 276-283.

Zhang R Z, Huang G B, Cai L Q, et al. 2013. Dry farmland practice involving multi-conservation tillage measures in the Loess Plateau. Chinese Journal of Eco-Agriculture, 21(1): 61-69. (in Chinese)

Zhang S, Li Q, Zhang X, et al. 2012. Effects of conservation tillage on soil aggregation and aggregate binding agents in black soil of Northeast China. Soil and Tillage Research, 124(4): 196-202.

Zhao X Z, Li F M, Mo F, et al. 2012. Integrated conservation solutions for the endangered Loess Plateau of Northwest China. Pakistan Journal of Botany, 44(3): 77-83.

Zheng H B, Liu W R, Zheng J Y, et al. 2018. Effect of long-term tillage on soil aggregates and aggregate-associated carbon in black soil of Northeast China. PloS ONE, 13(6): e0199523. 